BMJ Open

Ophthalmology

\title{
Pattern and prevalence of eye disorders and diseases in school-aged children: findings from the Nationwide School Sight Sampling Survey in Armenia
}

Nairuhi Jrbashyan (D) , ${ }^{1,2}$ Nune Yeghiazaryan, ${ }^{1}$ Abu Sikder (D) , ${ }^{3}$ Sudha Nallasamy, ${ }^{4}$ Mark W Reid, ${ }^{4}$ Roger Ohanesian, ${ }^{1,5}$ Thomas C Lee, ${ }^{4,6}$ Juan Espinoza (D) ${ }^{7,8}$

To cite: Jrbashyan $\mathrm{N}$, Yeghiazaryan N, Sikder A, et al. Pattern and prevalence of eye disorders and diseases in school-aged children: findings from the Nationwide School Sight Sampling Survey in Armenia. BMJ Open Ophthalmology 2022;7:e000899. doi:10.1136/ bmjophth-2021-000899

Received 6 September 2021 Accepted 25 January 2022

Check for updates

\section{(c) Author(s) (or their} employer(s)) 2022. Re-use permitted under CC BY-NC. No commercial re-use. See rights and permissions. Published by BMJ.

${ }^{1}$ Armenian EyeCare Project, Yerevan, Armenia

${ }^{2}$ Yerevan State University, Yerevan, Armenia

${ }^{3}$ Children's Hospital of Los Angeles, Los Angeles, California, USA

${ }^{4}$ Surgery, Children's Hospital of Los Angeles, Los Angeles, California, USA

${ }^{5}$ Department of Ophthalmology, UC Irvine, Irvine, California, USA ${ }^{6}$ Surgery, USC Keck School of Medicine, Los Angeles, California, USA

${ }^{7}$ Pediatrics, Children's Hospital of Los Angeles, Los Angeles, California, USA

${ }^{8}$ Pediatrics, USC Keck School of Medicine, Los Angeles, California, USA

\section{Correspondence to}

Dr Juan Espinoza; jespinoza@ chla.usc.edu

\section{ABSTRACT}

Objective This study aims to identify the prevalence of eye disorders and their causes among secondary schoolchildren aged 6-15 years old in Armenia, based on analysis of the Nationwide School Sight Sampling Survey. Methods and Analysis A two-stage proportionate stratified cluster sample was designed for the survey. 22 600 students were screened for visual acuity in schools; 5944 of them were selected for analysis as a nationally representative sample. Those with $20 / 40$ or worse vision were referred to photoscreening and rapid ophthalmic assessment in schools and then were provided with vouchers for free comprehensive eye examination in eye clinics. Data were collected through data collection forms and analysed using SPSS V.23.

Results While majority of the children (85\%) had normal vision, $15 \%$ had a visual acuity $\leq 20 / 40$. The prevalence of vision impairment $(\mathrm{VI})$ in at least one eye was $9.7 \%$ and blindness in at least one eye was $0.05 \%$. The prevalence of abnormal vision and VI was higher among girls and older children. VI was more prevalent in urban areas. The most common diagnoses were myopia (60\%), astigmatism (33.7\%), hyperopia (29.5\%) and strabismus (3.8\%).

Conclusion Majority of the vision abnormalities and $\mathrm{VI}$ among schoolchildren are a result of refractive error and are treatable. Our results highlight the importance of regular eye examinations for schoolchildren to detect and prevent VI. Raising awareness among parents, school staff and children about eye health is vital.

\section{INTRODUCTION}

Over 20 million children around the world are either blind or suffer from visual impairment. ${ }^{12}$ The prevalence and causes of visual impairment in children largely depend on the level of socioeconomic development of the country, availability and accessibility of ophthalmic care services, and behavioural patterns of the society. ${ }^{3}$ The global prevalence of blindness in children is estimated at 0.75 per 1000 children, with the highest level of 0.9 per 1000 in low-income countries compared with 0.7 in middle-income and 0.4 in high-income countries, respectively. ${ }^{4}$

\section{Key messages}

What is already known about this subject?

- A substantial number of children around the world 5-15 years of age are visually impaired from uncorrected or inadequately corrected refractive errors, and paediatric vision screening has been shown to be an effective tool to address this.

- School-based vision screening programmes have been particularly effective in low-income and middle-income countries (LMICs).

- Armenia, an LMIC, has very little information available on the prevalence of paediatric eye diseases and school-based vision screening programmes are lacking.

\section{What are the new findings?}

- Most Armenian schoolchildren with vision impairment (VI) suffer from refractive errors that are treatable.

School-based vision screening can help detect and prevent VI.

$>$ A continuum-of-care approach to help facilitate timely access to vision care is a promising solution to the paediatric eye care needs of Armenia.

\section{How might these results change the focus of} research or clinical practice?

School-based vision screening may be an appropriate and scalable solution for ameliorating VI in Armenian children.

$>$ Our continuum-of-care approach can serve as a model for other screening programmes that could be easily replicated throughout Armenia.

Most cases of childhood visual impairment are treatable and often preventable. Worldwide, nearly $1 \%$ of all children in the age group 5-15 years are visually impaired from uncorrected or inadequately corrected refractive errors. ${ }^{56}$ If left untreated, visual impairment among children can have a severe negative impact on their education, personal development and future economic productivity. $^{7}$ Innovative community-based 
strategies are required to provide quality services; periodic vision screening is imperative for detecting visual impairment and managing or preventing disease progression in children. ${ }^{2}$ As a pre-emptive measure, paediatric vision screening has shown to improve quality of life, educational outcomes, visual acuity (VA), prevention of disease and economic benefits, individually, nationally and globally. ${ }^{8}$ In particular, implementation of schoolbased vision screenings (SBVS) as part of school health programmes is highly recommended for low-income and middle-income countries (LMICs). ${ }^{78}$ Over the past two decades, more and more LMICs have implemented SBVS programmes. $^{9}$

Armenia is an upper-middle-income country situated in Western Asia with a population of 2.98 million, a per capita gross domestic product of US\$4732 and $26.4 \%$ poverty rate. ${ }^{10-12}$ Children are among the most vulnerable segments of the population, with nearly $34 \%$ of them living in poverty. ${ }^{11}$ There is very little information available on the prevalence of paediatric eye diseases and disorders in Armenia. The only official data available are on the incidence of 'diseases of eye and adnexa' (48.7 per 1000 children aged $0-14$ in 2019), which are collected and reported by the National Institute of Health of Armenia in their Health and Health Care Statistical Yearbook. ${ }^{13}$ This lack of data limits the possibility of implementing targeted eye care policies to ensure quality eye care for all children in the country.

Paediatric eye care in Armenia faces two major challenges: (1) optometry as a profession does not exist in Armenia, so all eye care are directed by ophthalmologists; and (2) majority of ophthalmologists are concentrated in Yerevan, the capital, which leaves children in the rest of the country with limited access to appropriate care. There are 10.8 ophthalmologists per 10000 children aged $0-14$ years old in Yerevan, compared with an average of 1.9 in the rest of the country. ${ }^{13}$ Given that the gross enrolment of children aged $6-15$ years old in public schools is high at $92 \%$, SBVS could serve as an effective approach to increasing access to eye health services among children in Armenia. ${ }^{14}$

The Armenian EyeCare Project (AECP), a nongovernmental organisation established in 1992, has been a leader in improving access to and quality of eye care services across the lifespan in Armenia. ${ }^{15-20}$ In 2018, the AECP, in collaboration with Children's Hospital Los Angeles, launched a new paediatric vision programme with two interconnected components. The School-Based Vision Screening Initiative (SBVS-I) was intended to reduce regional disparities in eye care through provision of a full cycle of comprehensive screening, diagnostic and treatment services to schoolchildren throughout Armenia. The Nationwide School Sight Sampling Survey (NS4) was designed to collect reliable data on eye diseases and disorders among school-aged children in Armenia through the SBVS-I to develop internationally recognised indicators of their prevalence. Here we present our analysis of the NS4 along with the prevalence of eye disorders and diseases with their causes among schoolchildren in Armenia for the first time since the 1990s.

\section{METHODS}

\section{Partnerships and programme development}

The SBVS-I and NS4 were implemented with a wide range of collaborators, among them the Ministries of Health, Education and Justice, regional government bodies in all regions of the country, community councils, school leaderships, teachers and school nurses, secondary and tertiary ophthalmological institutions and ophthalmologists, and parents or guardians. The Ministries of Education and Health supported the regulation of the overall process of involving schools and ophthalmological service providers in the programme. The Ministry of Justice provided expertise to ensure protection of children's rights and their personal data. Regional government bodies and community councils supported the arrangement of operational issues of the programme implementation at school sites. School leadership and staff collaborated in the screening organisation and implementation at school sites. Written informed consent was obtained from all parents for both vision screening and data collection efforts.

\section{Patient involvement}

Patients nor their parents were involved in the overall design of the vision screening procedures. However, parents were involved in consenting and providing demographic information and medical history of the child. Patients and families were not involved in the reporting or dissemination plans of the study.

\section{Design, sampling method and sample size}

In order to generate reliable and nationally representative prevalence data, a two-stage stratified cluster sample design using proportionate stratification was used. The sample frame was divided into three first-level strata: (1) Yerevan, (2) other urban areas and (3) rural areas. In each first-level stratum, the second level of stratification was applied by geographical zones: South-East, SouthWest, North-East, North-West and Central Yerevan. The applied sampling design ensured representativeness of the sample at national and strata levels. Public schools in Armenia were considered as clusters, and at the first stage of sampling procedure the clusters were selected by simple random sampling (SRS) in each stratum. For selecting clusters, the list of public schools obtained from the Ministry of Education was used as the sampling frame. Based on the average cluster sizes (100 students per cluster), 58 schools from all 10 regions of the country and Yerevan were selected as screening sites, representing $5 \%$ of all public schools providing secondary education in Armenia. At the second stage of sampling, the students in grades 1-9 were selected in each cluster using SRS from the student lists provided by each school. The SRS sample size was corrected by the design effect factor of 3.0. The sample size was estimated at 5944 students, assuming $5 \%$ degree of precision and $95 \%$ CI. To obtain 


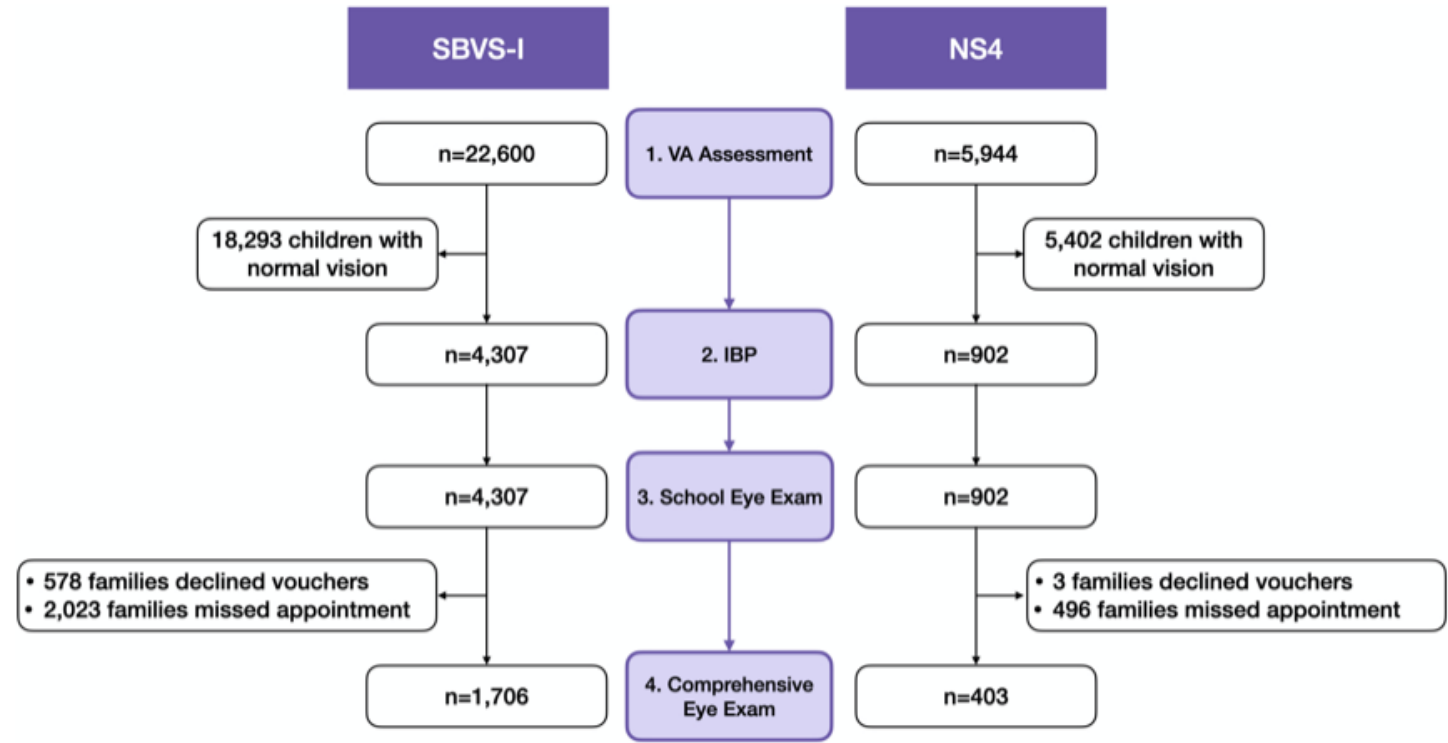

Figure 1 Screening flow diagram. IBP, instrument-based photoscreening; NS4, Nationwide School Sight Sampling Survey; SBVS-I, School-Based Vision Screening Initiative; VA, visual acuity.

the sample size, sampling unit replacement was done in cases where the selected student was absent on the day of screening or the parents did not sign the informed consent for their child's vision screening. The overall replacement rate was $1.7 \%$.

\section{Vision screening procedures}

Among children whose parents provided consent, vision screening consisted of a four-step process (figure 1).

\section{Step 1: VA assessment}

Initial screening was performed by an ophthalmologist and a nurse using a Snellen linear letter or linear picture vision chart at a distance of $6 \mathrm{~m}$. Each eye was tested independently and the opposite eye occluded with a hand. VA better than 20/40 in both eyes was considered normal and no further testing was performed. VA equal to or worse than 20/40 in either or both eyes was considered abnormal. Children with an abnormal VA screen, along with those whose VA was not possible to assess, proceeded to steps 2 through 4 .

\section{Step 2: instrument-based photoscreening}

Children were examined by a technical specialist using Spot Vision Screener (Welch Allyn, Skaneateles Falls, New York, USA) in a darkened room following standard manufacturer-recommended protocol. ${ }^{21}$ We used the following photoscreener settings: hyperopia $(\geq+2.50 \mathrm{D}$ spherical equivalent (SE)), myopia ( $\geq-1.00 \mathrm{D} \mathrm{SE})$, astigmatism $(\geq+1.00 \mathrm{D})$, anisometropia $(\geq+1.00 \mathrm{D} \mathrm{SE})$ and strabismus $\left(\geq 8.0^{\circ}\right)$.

\section{Step 3: ophthalmologist's examination at school}

An ophthalmologist was present and examined all children with an abnormal screen using an ophthalmoscope, with the primary goal of identifying a possible disease or disorder that required immediate attention. The ophthalmologist prepared a referral for every child for a comprehensive examination at a specialised eye clinic. Parents received a follow-up letter that described why their child needs comprehensive eye examination, an instrument-based photoscreening (IBP) results printout and a voucher for a no-cost comprehensive eye examination.

\section{Step 4: comprehensive eye examination in specialised eye clinics} All children identified with abnormal or unmeasurable VA received a voucher from the AECP for a free comprehensive eye examination within 2 months of their screening. These examinations were performed by ophthalmologists in 12 central and regional specialised eye clinics or departments, and included assessments of VA, sensorimotor examination, anterior segment evaluation, cycloplegic refraction and fundoscopic examination. The following definitions were used: low hyperopia $(\leq+2.25 \mathrm{D}$ $\mathrm{SE})$, moderate hyperopia $(+2.50 \mathrm{D}$ to $+5.00 \mathrm{D} \mathrm{SE})$, high hyperopia ( $\geq+5.25 \mathrm{D} \mathrm{SE})$, low myopia (0 to $-1.50 \mathrm{D} \mathrm{SE})$, moderate myopia $(-1.75 \mathrm{D}$ to $-5.75 \mathrm{D} \mathrm{SE})$, high myopia $(\leq-6.00 \mathrm{D} \mathrm{SE})$, astigmatism difference between the two main meridians of the eye $(\geq 1.00 \mathrm{D})$ and anisometropia difference of refractive power between eyes $(\geq+2.00 \mathrm{D}$ $\mathrm{SE})$.

\section{Data collection, data entry and statistical analysis}

Demographics and medical history were reported by parents on behalf of their children using a paper form that was completed at home prior to screening. VA assessment and school-based ophthalmology examination results were recorded on paper forms by AECP staff. IBP results were exported from the device into MS Excel (Microsoft, Redmond, Washington). Comprehensive eye examination results were recorded on a paper data collection form by the performing ophthalmologist 
at the specialised eye clinics. All data from paper forms were transcribed to an electronic database and anonymised for analysis. Statistical analyses were performed using SPSS V.23. The NS4 VA acuity data set was weighted to adjust cases to the main proportions in the SBVS-I. VA and visual impairment classification was analysed based on the eleventh revision of the International Classification of Diseases (ICD-11) for Mortality and Morbidity Statistics Version 04/2019 standards. ${ }^{22}$ Welch Allyn (WA) photoscreening results were analysed based on refractive error classification and WA device refraction standards. ${ }^{21}$

\section{RESULTS}

\section{School-Based Vision Screening Initiative}

Implemented during the 2018-2019 school year, the SBVS-I performed eye screenings for 22600 public school students enrolled in grades 1-9 (aged 6-15 years) across 58 public schools throughout Armenia, or $7.3 \%$ of all students of this category. Of the children, 4307 (19\%) had an abnormal screen or were not able to be assessed. The remaining 18293 (81\%) had a normal vision screen and no further testing was performed. Parents of 3729 out of 4307 children agreed to visit an eye clinic for a comprehensive eye examination using an AECP voucher. Of these, $1706(45.7 \%)$ attended their appointment and received the comprehensive eye examination; the remaining children were not brought in for evaluation to any clinic working with the AECP during the 2-month follow-up period. Among the 1706 children who did have comprehensive eye examinations, $48 \%$ were from Yerevan and 52\% were from the regions.

\section{Nationwide School Sight Sampling Survey}

The NS4 cohort was assembled from 5944 students who participated in the SBVS-I. Of these, 902 (15.2\%) had abnormal vision or were not able to be assessed. These children were referred to all next phases of the screening and were provided with WA photoscreening and an ophthalmologist's examination at the school. Out of these 902 children, parents of 899 agreed to visit an eye clinic for a comprehensive eye examination and received a voucher. Of these, 403 went on to visit a clinic and were provided with a comprehensive eye examination.

\section{Demographic characteristics of NS4 participants}

The NS4 cohort was assembled from 5944 schoolchildren living in all regions of Armenia and Yerevan who participated in the SBVS-I. The distribution of surveyed children by first-level and second-level strata corresponds to the overall distribution of schoolchildren enrolled in public secondary schools (table 1). Gender distribution of NS4 participants ( $48.9 \%$ female, $51.1 \%$ male) corresponds to the general gender breakdown of the children enrolled in public schools, which in 2018 was $49 \%$ female and $51 \%$ male. $^{13}$ Of the participants, $2673(45 \%)$ were between 6 and 10 years old, and $3271(55 \%)$ were between 11 and 15 years old. This age distribution is very comparable with the overall age distribution of children in primary and middle public schools in Armenia: $47.8 \%$ and $52.2 \%$, respectively. ${ }^{11}$ The mean age of the surveyed children was 10.2 years $(\mathrm{SD}=2.4)$.

\section{VA and ocular disorders}

VA assessment

Among the 5944 NS4 participants, 5042 (84.8\%) had normal VA. Of the remaining schoolchildren, $892(15 \%)$ had an abnormal VA screen and $10(0.2 \%)$ were unable to be assessed. Of the 5934 students who were able to participate in VA screening, $316(5.3 \%)$ had VA of exactly $20 / 40$ in at least one eye or better, $573(9.7 \%)$ had a VA $<20 / 40$ and $\geq 20 / 400$, and $3(0.05 \%)$ had blindness (VA <20/400). Table 2 shows the breakdown of students by severity of vision impairment (VI), as well as by gender, age and location (due to small differences in weighting related to sampling design, the total VI does not equal the sum of each row). The prevalence of VI was higher among girls and children aged 10-15 years old. The $p$ value of the two-sided $\chi^{2}$ test indicates a significant association between gender and VI and between

\begin{tabular}{|c|c|c|c|}
\hline & & National population & NS4 participants \\
\hline Strata & Geographical region & $\begin{array}{l}\text { Children aged } 6-15 \text { years old in } \\
\text { public schools, } n(\%)\end{array}$ & $\begin{array}{l}\text { Children aged } 6-15 \text { years } \\
\text { old in public schools, } n(\%)\end{array}$ \\
\hline \multirow[t]{4}{*}{1} & Yerevan & $99101(32.1)$ & $1908(32.1)$ \\
\hline & Other urban areas & $97484(31.6)$ & $1877(31.6)$ \\
\hline & Rural areas & $111714(36.2)$ & 2159 (36.3) \\
\hline & Total & $308299(100)$ & $5944(100)$ \\
\hline \multirow[t]{6}{*}{2} & Zone 1: Central (Yerevan) & $99101(32.1)$ & $1908(32.1)$ \\
\hline & Zone 2: North-West (Shirak, Aragatsotn, Kotayk) & $70401(22.8)$ & $1356(22.8)$ \\
\hline & Zone 3: North-East (Gegarkuniq, Tavush, Lori) & $62645(20.3)$ & $1208(20.3)$ \\
\hline & Zone 4: South-West (Ararat, Armavir) & $57438(18.6)$ & $1104(18.6)$ \\
\hline & Zone 5: South-East (Vaiots Dzor, Syuniq) & $18714(6.1)$ & $368(6.2)$ \\
\hline & Total & $308299(100)$ & $5944(100)$ \\
\hline
\end{tabular}

NS4, Nationwide School Sight Sampling Survey. 
Table 2 Visual acuity among schoolchildren aged 6-15 years in the NS4 cohort

\begin{tabular}{|c|c|c|c|c|c|}
\hline & $\begin{array}{l}\text { Mild vision impairment, } \\
20 / 40>V A \geq 20 / 70 \\
n(\%)\end{array}$ & $\begin{array}{l}\text { Moderate vision impairment, } \\
20 / 70>V A \geq 20 / 200 \\
\text { n }(\%)\end{array}$ & $\begin{array}{l}\text { Severe vision impairment, } \\
20 / 200>V A \geq 20 / 400 \\
n(\%)\end{array}$ & $\begin{array}{l}\text { Total vision impairment, } \\
20 / 40>\mathrm{VA} \geq 20 / 400 \\
\mathrm{n}(\%)\end{array}$ & $\begin{array}{l}\text { Blindness, } \\
\text { VA<20/400 } \\
n(\%)\end{array}$ \\
\hline \multicolumn{6}{|l|}{ All children } \\
\hline $\begin{array}{l}\text { Monocular (other eye } \\
\text { normal) }\end{array}$ & $180(3)$ & $76(1.3)$ & $5(0.1)$ & $261(4.4)$ & $2(0.03)$ \\
\hline Binocular (worst eye) & $124(2.1)$ & $181(3.1)$ & $6(0.1)$ & $312(5.3)$ & $1(0.02)$ \\
\hline In at least one eye & $367(6.2)$ & $261(4.4)$ & $11(0.2)$ & $573(9.7)$ & $3(0.05)$ \\
\hline \multicolumn{6}{|c|}{ Subgroup analyses (in at least one eye) } \\
\hline \multicolumn{6}{|l|}{ Gender } \\
\hline Female & $194(6.7)$ & $144(5)$ & $5(0.2)$ & $312(10.8)$ & $1(0.02)$ \\
\hline Male & $172(5.6)$ & 117 (3.9) & $6(0.2)$ & $261(8.5)$ & $2(0.08)$ \\
\hline \multicolumn{6}{|l|}{ Age group (years) } \\
\hline $6-10$ & $127(3.8)$ & $90(2.7)$ & $2(0.1)$ & $194(5.8)$ & $0(0)$ \\
\hline $11-15$ & $239(9.2)$ & $171(6.6)$ & $9(0.4)$ & $379(14.5)$ & $3(0.05)$ \\
\hline \multicolumn{6}{|l|}{ Geographical region } \\
\hline Yerevan & $152(8)$ & $102(5.4)$ & $4(0.2)$ & $230(12.1)$ & $1(0.05)$ \\
\hline Other urban areas & $121(6.5)$ & $75(4)$ & $5(0.3)$ & $180(12.4)$ & $1(0.04)$ \\
\hline Rural areas & $93(4.3)$ & 84 (3.9) & $2(0.1)$ & $163(7.5)$ & $1(0.06)$ \\
\hline
\end{tabular}

NS4, Nationwide School Sight Sampling Survey; VA, visual acuity.

age groups and VI (both $\mathrm{p}=0.003$ ). The prevalence of VI was highest in Yerevan and other urban areas compared with rural areas $(12.1 \%$ and $12.4 \%$ vs $7.5 \%$, respectively). The $\chi^{2}$ test $(p=0.000)$ indicated significant association between the living area of children (urban, rural, Yerevan) and VI. Compared with self-reported medical history, only half $(50.2 \%)$ of the parents of children with VI mentioned that their children had known vision problems. The awareness of parents of children aged 6-9 years old with VI was lower $(40.7 \%)$ compared with parents of children aged 11-15 years old $(52.7 \%)$. In urban areas, the awareness of parents of children with VI was much higher $(63.8 \%$ in Yerevan and $46.9 \%$ in other urban areas) compared with $34.8 \%$ in rural areas. There were no statistically significant differences between awareness of vision problems among parents of girls compared with boys.

\section{Instrument-based photoscreening}

Of the students, 902 underwent IBP. In seven cases, the device could not be applied successfully; IBP was completed in 895 children. Of the students, 590 (9.9\% of all NS4 participants and $66 \%$ of successfully photoscreened children) were found to have refractive errors and were flagged for a complete visual examination. Overall, the most common IBP-guided diagnoses (alone or in combination) in the NS4 cohort were myopia $(6.2 \%)$, astigmatism $(3.0 \%)$, anisometropia $(2.7 \%)$, hyperopia $(0.9 \%)$ and strabismus $(0.6 \%)$. The remaining 305 (34.1\% of successfully photoscreened children) had a normal IBP.

Among the 590 children with VI on IBP, $33.3 \%$ had myopia alone, $10.2 \%$ had astigmatism alone, $3.4 \%$ had anisometropia alone, $1.7 \%$ had strabismus alone, $0.9 \%$ had hyperopia alone and $0.2 \%$ had anisocoria alone, while $28 \%$ had two or more diagnoses. Myopia was the most prevalent refractive error, present in 53\% of children with VI alone or in combination with another diagnosis.

\section{Comprehensive eye examination}

All 902 students with abnormal or incomplete VA assessment were evaluated by an ophthalmologist at the school on the day of screening to rule out urgent eye disease. Of them, 899 were provided with referrals and vouchers to receive free comprehensive eye examinations in eye clinics (in 3 cases, the parents refused to receive vouchers). Of these, 403 (44.8\%) followed up and had the examination performed. These patients were evenly distributed across Yerevan (33.3\%), other urban areas $(34.7 \%)$ and rural areas (32\%). Diagnostic data from ophthalmologists' examinations were available for 365 children (table 3 ). The majority of children had treatable refractive errors, including myopia (60\%), astigmatism $(33.7 \%)$ and hyperopia (29.5\%). A smaller group of children were found to have strabismus, amblyopia and other diagnoses separately or in combination with refractive errors. Overall, 317 of 365 (86.8\%) children had refractive errors, while $28(7.7 \%)$ children had a normal comprehensive eye examination with no evidence of VI or other eye disorders.

\section{Evaluation of IBP sensitivity}

Out of 576 cases with VI and blindness detected during VA screenings in schools, $128(22.3 \%)$ passed the IBP successfully. Out of 143 cases, 29 (20.3\%) with VI or other relevant diagnoses on comprehensive eye examination had a normal IBP. This suggests that approximately $20 \%-25 \%$ of IBP results in this study could be considered false negatives. Compared with comprehensive eye examination, the sensitivity of the Spot Vision Screener in our 
Table 3 Comprehensive eye examination findings

\begin{tabular}{lcc}
\hline $\begin{array}{l}\text { Comprehensive eye } \\
\text { examination findings ( } \mathbf{n}=\mathbf{3 6 5} \\
\text { patients) }\end{array}$ & Patients, $\mathbf{n}$ (\%) & Passed IBP, $\mathbf{n}$ \\
\hline Amblyopia & $9(2.5)$ & 0 \\
\hline Low hyperopia* & $75(20.5)$ & $\mathrm{n} / \mathrm{a}$ \\
\hline Moderate hyperopia† & $25(6.8)$ & $\mathrm{n} / \mathrm{a}$ \\
\hline High hyperopia & $11(3)$ & 2 \\
\hline Low myopia & $187(51.2)$ & 25 \\
\hline Moderate myopia & $28(7.7)$ & 12 \\
\hline High myopia & $4(1.1)$ & 3 \\
\hline Strabismus & $13(3.8)$ & 2 \\
\hline Astigmatism & $123(33.7)$ & 17 \\
Anisometropia & $3(0.8)$ & 0 \\
Congenital cataract & $1(0.3)$ & 0 \\
Congenital glaucoma & $1(0.3)$ & 0 \\
\hline
\end{tabular}

*Findings in at least one eye, alone or in combination with other findings.

tLow and moderate hyperopia cases were counted only if they were diagnosed in combination with other diagnoses.

IBP, instrument-based photoscreening; n/a, not available.

study was $52 \%$ for astigmatism (64 of 123 cases), $66.2 \%$ for myopia (145 of 219 cases), $61.5 \%$ for strabismus ( 8 of 13 cases) and $63.6 \%$ for hyperopia (7 of 11 cases).

\section{DISCUSSION}

This study represents the largest and most rigorous evaluation to date of VA among children aged 6-15 years old in Armenia since its independence in 1991. The SBVS-I successfully screened 22600 children in every region of Armenia, from which a nationally representative NS4 cohort of 5944 children was derived. Overall, $15 \%$ of children failed the initial VA screen; $9.7 \%$ were found to have some form of visual impairment and $0.05 \%$ had blindness. The majority of children with VI had treatable refractive errors. The study revealed a statistically significant association between gender, age and geographical region and prevalence of VI. Girls, children aged 10-15 years old, and children living in Yerevan and other urban areas all had higher prevalence of VI. This urban-rural difference is consistent with other published studies. ${ }^{23}$

There are very few studies of VA among schoolchildren in Armenia. In 2000, the American University of Armenia conducted the Summer Camps Visual Impairment Project, which screened 3307 children aged 6-17 attending summer camp in three regions of Armenia, and found that $11 \%$ had refractive errors. ${ }^{24}$ A 2011 study of 112 socially vulnerable children in Yerevan reported an $18.8 \%$ prevalence of refractive errors. ${ }^{25}$ Finally, in 2017, Giloyan $e t a l^{26}$ screened 1260 schoolchildren in Yerevan and Gegharkunik (a rural area) as part of their study to assess the prevalence of risk factors for developing myopia and found a prevalence of $18 \%$ for myopia, $3.4 \%$ for hyperopia and $3.2 \%$ for astigmatism. Similar to our research, they also reported that children living in Yerevan had more VI.

Throughout the world, VI impacts children and their families, hindering academic success, career opportunities and social life. ${ }^{27}$ Programmes to screen school-aged children in LMICs, while challenging, can be safe and effective tools to reduce the burden of VI and decrease healthcare costs, and have been implemented in several countries. ${ }^{128-30}$ Table 4 provides a brief summary of a sample of other SBVS studies for context. ${ }^{31-38}$ Our study is comparable with others in terms of size and scope, with VI and refractive error prevalence within the same range. It is important to note that there is significant variability across studies in protocols, diagnostic definitions and data collection, so there are limitations to the generalisability of the findings of any one study. The underlying causes of visual impairment are heterogeneous and include genetic, developmental, environmental and socioeconomic factors, further limiting how meaningful it might be to compare across countries. ${ }^{23}$

A significant strength of our initiative is the continuumof-care approach applied to the SBVS algorithm, which ensured that all children with an abnormal screen had access to additional services, including IBP, same-day evaluation with an ophthalmologist in school and vouchers

\begin{tabular}{|c|c|c|c|c|c|c|c|}
\hline Study & Country & $\begin{array}{l}\text { Publication } \\
\text { year }\end{array}$ & $\begin{array}{l}\text { Age } \\
\text { (years) }\end{array}$ & $\begin{array}{l}\text { Sample } \\
\text { size }(n)\end{array}$ & $\begin{array}{l}\text { VI } \\
\text { threshold }\end{array}$ & $\begin{array}{l}\text { Prevalence of } \\
\text { VI (\%) }\end{array}$ & $\begin{array}{l}\text { Prevalence of refractive } \\
\text { errors (\%) }\end{array}$ \\
\hline Megbelayin and Asana ${ }^{31}$ & Nigeria & 2013 & $9-21$ & 1175 & $\leq 6 / 9$ & 6.9 & 51 \\
\hline Kumah et $\left.a\right|^{32}$ & Ghana & 2013 & $12-15$ & 2435 & $\leq 6 / 12$ & 3.7 & 71.7 \\
\hline Naidoo et $\mathrm{a}^{33}$ & South Africa & 2003 & $5-15$ & 4890 & $\leq 6 / 12$ & 1.4 & 63.6 \\
\hline Murthy et $\left.a\right|^{34}$ & India & 2002 & $5-15$ & 6447 & $\leq 6 / 12$ & 6.4 & 81.7 \\
\hline Paudel et $\left.a\right|^{35}$ & Vietnam & 2014 & $12-15$ & 2238 & $\leq 6 / 12$ & 19.4 & 92.7 \\
\hline Hashim et $a l^{36}$ & Malaysia & 2008 & $6-12$ & 712 & $\leq 6 / 12$ & 7.7 & 90.7 \\
\hline Salomao et $a l^{37}$ & Brazil & 2018 & $11-14$ & 2441 & $\leq 6 / 12$ & 4.8 & 76.8 \\
\hline Sauer et $a^{38}$ & Peru & 2016 & $5-18$ & 380 & $\leq 6 / 9$ & 8.9 & Not reported \\
\hline Current study & Armenia & 2021 & $6-15$ & 5934 & $\leq 6 / 12$ & 9.7 & 86.8 \\
\hline
\end{tabular}

LMICs, low-income and middle-income countries; SBVS, school-based vision screening; VI, vision impairment. 
for free comprehensive eye examinations at nearby specialised eye clinics. This approach is new for Armenia and can serve as a model for government-led public health initiatives for periodic eye screenings in schools. Our experience during the COVID-19 global pandemic has helped us identify ways in which this programme could be changed to minimise personal contact by using telemedicine and telehealth, mobile apps, etc. This 'digitization' of SBVS could be synergistic with other initiatives in Armenia meant to provide children and their families with more health literacy resources and connect individuals to healthcare services through the internet. Other strengths of this study include its large, nationally representative sample size, robust statistical design and cross-sector collaboration with multiple stakeholders.

The sensitivity of our IBP was lower than other studies in the literature. Barugel $e t a l^{39}$ reported that the sensitivity of the Spot Vision Screener in detecting myopia was $84.61 \%$ and for astigmatism $78.57 \%$, while we found sensitivities of $66 \%$ and $52 \%$, respectively. Peterseim et $a l^{40}$ found a sensitivity of $77.17 \%$ in detecting strabismus compared with $61 \%$ in our study. ${ }^{40}$ Other studies consistently report overall sensitivity for detecting refractive errors to be greater than $80 \% .{ }^{39-42}$ One possible explanation for the lower sensitivity in our study was the IBP settings. For example, the cut-off for myopia on IBP was $\geq-1.00 \mathrm{D}$ (consistent with local practice in Armenia), but the comprehensive eye examination could have detected lower values. Given the differences in populations, methods and analyses, it is difficult to interpret this difference in sensitivity findings, but they may represent an opportunity to optimise our implementation of and adherence to IBP protocols.

There are certain limitations to our study. All forms, including demographic surveys, medical histories and voucher forms, were completed by hand by parents, so in some cases information was missing or illegible. Among the 403 children who had comprehensive eye examinations, complete data were only available for analysis for 365 of them, representing nearly $10 \%$ data loss. The voucher system, while innovative, also had setbacks. Only about half of all families issued a voucher actually had a comprehensive eye examination, despite being provided information about the importance of further evaluation and treatment. One reason for this is that parents would have had to travel to the nearest city or the capital to be examined, which could be a significant limitation for some families in rural regions. It is possible that some families received follow-up care with an ophthalmologist not associated with our study or organisation, although this is less likely in rural regions where the AECP may be the only provider of eye health services. Lack of parental awareness of childhood visual disorders and their consequences may have also played a role. ${ }^{16}$ Half of parents were not aware that their children had VI, according to self-reported data. This further suggests that a significant number of schoolchildren do not undergo appropriate visual examination on admission to school or periodically thereafter, despite the existence of relevant requirements.

\section{CONCLUSION}

Our results show that a national SBVS programme is feasible in Armenia. For the first time since the 1990s, new data are available to calculate the prevalence of VI and blindness among Armenian schoolchildren aged 6-15 years old. This study shows that the majority of visual abnormalities among this population are due to treatable refractive errors. Our findings stress the importance of regular eye examinations of schoolchildren for early detection, prevention and treatment of VI. The continuum-of-care approach can serve as a model for other screening programmes and could be easily replicated throughout Armenia. Finally, there is a need for additional public education raising awareness among parents, school staff and children about vision problems and the importance of eye health.

Acknowledgements The authors would like to acknowledge the Armenian EyeCare Project team members who helped make this project possible. The authors would also like to express their gratitude to all the members of the OPEN/ Avetis Team at Children's Hospital Los Angeles for their camaraderie and support.

Contributors NJ, NY, RO, TCL and JE developed and managed the programme described in the study. NJ, NY, JE and AS created the outline and initial draft of the manuscript. MWR and SN contributed to editing of the manuscript and provided feedback and subject matter expertise. NJ, AS and JE developed the tables and figure. NJ performed the statistical analysis. All authors contributed to manuscript revision and read and approved the submitted version.

Funding This project was funded by an anonymous philanthropic donor.

Competing interests JE is a paid consultant for Al Health. Al Health had no role in the design or execution of this work, the decision to publish or any editorial oversight.

Patient and public involvement Patients and/or the public were not involved in the design, or conduct, or reporting, or dissemination plans of this research.

Patient consent for publication Not required.

Ethics approval This study received IRB approval (\#CHLA-20-00306) from Children's Hospital Los Angeles as an exempt study.

Provenance and peer review Not commissioned; internally peer reviewed.

Data availability statement Data are available upon reasonable request. All data were collected and stored in Armenia and under applicable Armenian laws and regulations. Data requests will be reviewed for compliance with appropriate local laws and regulations.

Open access This is an open access article distributed in accordance with the Creative Commons Attribution Non Commercial (CC BY-NC 4.0) license, which permits others to distribute, remix, adapt, build upon this work non-commercially, and license their derivative works on different terms, provided the original work is properly cited, appropriate credit is given, any changes made indicated, and the use is non-commercial. See: http://creativecommons.org/licenses/by-nc/4.0/.

\section{ORCID iDs}

Nairuhi Jrbashyan http://orcid.org/0000-0002-8844-7514

Abu Sikder http://orcid.org/0000-0002-8300-479X

Juan Espinoza http://orcid.org/0000-0003-0513-588X

\section{REFERENCES}

1 Burnett AM, Yashadhana A, Lee L, et al. Interventions to improve school-based eye-care services in low- and middleincome countries: a systematic review. Bull World Health Organ 2018;96:682-94.

2 Honavar SG. Pediatric eye screening - why, when, and how. Indian J Ophthalmol 2018;66:889-92. 
3 Gilbert C, Foster A. Childhood blindness in the context of vision 2020--the right to sight. Bull World Health Organ 2001;79:227-32.

4 World Health Organization Blindness and Deafness Unit \& International Agency for the Prevention of Blindness. Preventing blindness in children : report of a WHO/IAPB scientific meeting, Hyderabad, India. Geneva: World Health Organization, 1999. https:// apps.who.int/iris/handle/10665/66663

5 Resnikoff S, Pascolini D, Mariotti SP, et al. Global magnitude of visual impairment caused by uncorrected refractive errors in 2004. Bull World Health Organ 2008;86:63-70.

6 Zhou Z, Kecman M, Chen T, et al. Spectacle design preferences among Chinese primary and secondary students and their parents: a qualitative and quantitative study. PLoS One 2014;9:e88857-8.

7 National Academies of Sciences and Medicine E. Making eye health a population health imperative: vision for tomorrow. National Academies Press, 2017.

8 World Bank, Global Partnership for Education. Guidelines for schoolbased eye health programmes 2018.

9 Adhisesha Reddy P, Bassett K. Visual acuity screening in schools: a systematic review of alternate screening methods. Cogent Med 2017:4:1371103

10 The World Bank. GDP per capita (current US\$), 2021. Available: https://data.worldbank.org/indicator/NY.GDP.PCAP.CD [Accessed 21 Jan 2021].

11 The World Bank; Statistical Committee of the Republic of Armenia. Social snapshot and poverty in Armenia, 2020: 1-5.

12 Ministry of Foreign Affairs of the Republic of Armenia. General information about Republic of Armenia. Available: https://www.mfa. am/en/overview [Accessed 10 Jan 2022].

13 Armenian M of H. Statistical year book health and healthcare 2017 Yerevan, 2017.

14 Statistical Committee of the Republic of Armenia. Social situation of RA in 2018, 2018. Available: https://armstat.am/en/?nid=82\&id=2182 [Accessed 7 Feb 2021].

15 The Armenian EyeCare Project. Armenian EyeCare project: bringing sight to Armenian eyes, 2021. Available: https://eyecareproject.com/ [Accessed 7 Feb 2021].

16 Hill R, Ohanesian R, Voskanyan L, et al. The Armenian eye care project: surgical outcomes of complicated paediatric glaucoma. $\mathrm{Br} \mathrm{J}$ Ophthalmol 2003;87:673-6.

17 Sarin-Gulian L, Espinoza J, Lee TC, et al. Development and evaluation of a Tele-Education program for neonatal ICU nurses in Armenia. J Pediatr Nurs 2021;57:e9-14.

18 Hovhannisyan A, Fink C, Brown A. The incidence of retinopathy of prematurity in Armenia. Invest Ophthalmol Vis Sci 2013;54:595.

19 Lee T. Telementoring: how technology is helping to lower the impact of ROP in Armenia: High-bandwidth, high-resolution platforms allow experts to observe the surgical field remotely, as though they were there. Retin Today 2015;2015:58-60.

20 Lee T. Using telemedicine to save more than sight in premature infants. Retin. physician, 2017. Available: https://www. retinalphysician.com/issues/2017/july-august-2017/usingtelemedicine-to-save-more-than-just-sight-in [Accessed 7 Feb 2021].

21 Welch Allyn. Welch Allyn spot vision Screener model VS100, 2019.

22 World Health Organization. ICD-11 for Mortality and Morbidity Statistics (Version : 04 / 2019), 2019. Available: https://icd.who.int/ browse11_2019-04/I-m/en [Accessed 7 Feb 2021].

23 Morgan I, Rose K. How genetic is school myopia? Prog Retin Eye Res 2005;24:1-38.
24 Khachatryan N, Thompson ME AM. Summer camps visual impairment project: final report to Unites Methodist relief Society, 2000.

25 Giloyan A, Petrosyan V. Refractive errors and nutritional status among socially vulnerable school children in Yerevan, Armenia. Eur J Public Health 2014;24.

26 Giloyan A, Harutyunyan T, Petrosyan V. Risk factors for developing myopia among schoolchildren in Yerevan and Gegharkunik Province, Armenia. Ophthalmic Epidemiol 2017;24:97-103.

27 Atowa UC, Hansraj R, Wajuihian SO. Visual problems: a review of prevalence studies on visual impairment in school-age children. Int $J$ Ophthalmol 2019;12:1037-43.

28 Baltussen R, Naus J, Limburg H. Cost-effectiveness of screening and correcting refractive errors in school children in Africa, Asia, America and Europe. Health Policy 2009;89:201-15.

29 Opare A, Abdullahi LH, Minnies D, et al. School vision screening programmes in reducing uncorrected refractive error among children in low and middle-income countries-LMIC (systematic review). Adv Ophthalmol Vis Syst 2020;10:91-105.

30 Qureshi JS, Samuel J, Lee C, et al. Surgery and global public health: the UNC-Malawi surgical initiative as a model for sustainable collaboration. World J Surg 2011;35:17-21.

31 Megbelayin O, Asana E. Visual impairment among schoolchildren calabar vision screening survey in secondary schools (CVS4 study). Internet J Ophthalmol Vis Sci 2013:10:1-7.

32 Kumah BD, Ebri A, Abdul-Kabir M, et al. Refractive error and visual impairment in private school children in Ghana. Optom Vis Sci 2013;90:1456-61.

33 Naidoo KS, Raghunandan A, Mashige KP, et al. Refractive error and visual impairment in African children in South Africa. Invest Ophthalmol Vis Sci 2003;44:3764-70.

34 Murthy GVS, Gupta SK, Ellwein LB, et al. Refractive error in children in an urban population in New Delhi. Invest Ophthalmol Vis Sci 2002;43:623-31.

35 Paudel P, Ramson P, Naduvilath T, et al. Prevalence of vision impairment and refractive error in school children in Ba Ria - Vung Tau province, Vietnam. Clin Exp Ophthalmol 2014;42:217-26.

36 Hashim S-E, Tan H-K, Wan-Hazabbah WH, et al. Prevalence of refractive error in Malay primary school children in suburban area of Kota Bharu, Kelantan, Malaysia. Ann Acad Med Singap 2008;37:940-6.

37 Salomão SR, Cinoto RW, Berezovsky A, et al. Prevalence and causes of visual impairment in low-middle income school children in Sao Paulo, Brazil. Invest Ophthalmol Vis Sci 2008;49:4308-13.

38 Sauer T, Martin M, Alarcon JA, et al. Prevalence of vision impairment in school children of Puente Piedra, Peru. Vis Pan-America PanAmerican J Ophthalmol 2016;15.

39 Barugel R, Touhami S, Samama S, et al. Evaluation of the spot vision screener for children with limited access to ocular health care. $J$ Aapos 2019;23:153.e1-153.e5.

40 Peterseim MMW, Davidson JD, Trivedi R, et al. Detection of strabismus by the spot vision Screener. J Aapos 2015;19:512-4.

41 Matta NS, Silbert DI, International Orthoptic Association Vision Screening Committee. Vision screening across the world. Am Orthopt J 2012;62:87-9.

42 Silbert DI, Matta NS. Performance of the spot vision screener for the detection of amblyopia risk factors in children. $J$ Aapos 2014;18:169-72. 